\title{
Expression of chromosomal regional maintenance protein-1 may be associated with subcellular survivin expression in human gastric and colorectal carcinoma
}

\author{
MICHIKO SHINTANI ${ }^{1}$, AKITO TASHIRO ${ }^{1}$, AKIKO SANGAWA ${ }^{2}$, NAOKI YAMAO ${ }^{3}$ and SHINGO KAMOSHIDA $^{1}$ \\ ${ }^{1}$ Laboratory of Pathology, Division of Medical Biophysics, Kobe University Graduate School of Health Sciences, \\ Kobe, Hyogo 654-0142; ${ }^{2}$ Department of Diagnostic Pathology, Osaka Red Cross Hospital, Osaka 543-8555; \\ ${ }^{3}$ Department of Clinical Laboratory, Kuma Hospital, Kobe, Hyogo 650-0011, Japan
}

Received March 13, 2015; Accepted April 22, 2016

DOI: $10.3892 / \mathrm{ol} .2016 .5220$

\begin{abstract}
Survivin, a member of the inhibitor of apoptosis protein family, is a potential prognostic marker and molecular target for anticancer therapies. Chromosomal regional maintenance protein-1 (CRM-1) mediates the nuclear export of proteins such as survivin. The aims of the present study were to compare the expression and subcellular localization of CRM-1 in human gastric and colorectal carcinomas and to assess the association between CRM-1 and survivin expression in these tumor types. The nuclear and cytoplasmic CRM-1 expression rates in gastric carcinoma were $61 \%$ (42/69) and 29\% (20/69), respectively, while the nuclear and cytoplasmic CRM-1 expression rates in colorectal carcinoma were 55\% (43/78) and 37\% (29/78), respectively. Nuclear and cytoplasmic CRM-1 expression was found to be significantly correlated with nuclear and cytoplasmic survivin expression in colorectal carcinoma, but not gastric carcinoma. These results indicate that CRM-1 expression patterns differ between gastric and colorectal carcinomas and thus, we hypothesize that CRM-1-mediated nuclear export of survivin may be deregulated in gastric carcinoma. Therefore, CRM-1 may exhibit different functions in gastric and colorectal carcinoma.
\end{abstract}

\section{Introduction}

As a member of the inhibitor of apoptosis protein family, survivin resides in both the nucleus and cytoplasm of cells. Survivin controls both cell division (when localized to the

Correspondence to: Dr Michiko Shintani, Laboratory of Pathology, Division of Medical Biophysics, Kobe University Graduate School of Health Sciences, 7-10-2 Tomogaoka, Suma-ku, Kobe, Hyogo 654-0142, Japan

E-mail: mtshin@kobe-u.ac.jp

Key words: survivin, chromosomal regional maintenance protein-1, gastric carcinoma, colorectal carcinoma, immunohistochemistry nucleus) and cell survival (when localized to the cytoplasm) and thus may exhibit a dual function (1-3). In normal adult tissues survivin is usually undetectable, however it is overexpressed in the majority of human tumors, including lung, colon, breast, stomach and liver cancer (4-9). Due to its involvement in tumorigenesis, survivin has been proposed as a prognostic marker and a molecular target for anticancer therapies (10-13).

Survivin shuttles between the nucleus and cytoplasm, and several studies have demonstrated that chromosomal regional maintenance protein-1 (CRM-1) regulates its subcellular distribution $(2,3,12,13)$. CRM-1, a member of the importin B superfamily, exports both proteins and mRNAs from the nucleus and is the main nuclear exporter in humans. It recognizes a leucine-rich nuclear export signal in proteins and exports proteins, including survivin, via the CRM-1/Ras-related nuclear protein-guanosine-5'-triphosphate axis (14-17). High CRM-1 expression has been identified in several malignancies, including stomach, pancreatic, ovarian, cervical, renal and esophageal cancers. Its presence in tumor cells indicates that it predicts an unfavorable prognosis (18-23).

At present, cancer is the primary cause of mortality in Japan (24). In 2011, a total of 132,000 and 125,000 cases of gastric and colorectal cancer were diagnosed, respectively (25). Furthermore, gastric and colorectal cancer accounted for 47,903 and 48,500 mortalities in 2014, respectively (25). Gastric cancer remains a significant cause of cancer-related mortality (24). Our previous study demonstrated that nuclear and cytoplasmic survivin expression was higher in colorectal carcinomas than gastric carcinomas (26). The levels of nuclear and cytoplasmic survivin are directly correlated in colorectal carcinoma, but not gastric carcinomas. However, the effect of survivin localization remains unclear and thus, further study of survivin/CRM-1 interaction with regard to tumorigenesis is required (27-29).

The aims of the present study were to compare the expression levels and intracellular localization of CRM-1 in human gastric and colorectal carcinomas and to investigate the association between CRM-1 and survivin expression. In this study, CRM-1 expression was assessed 

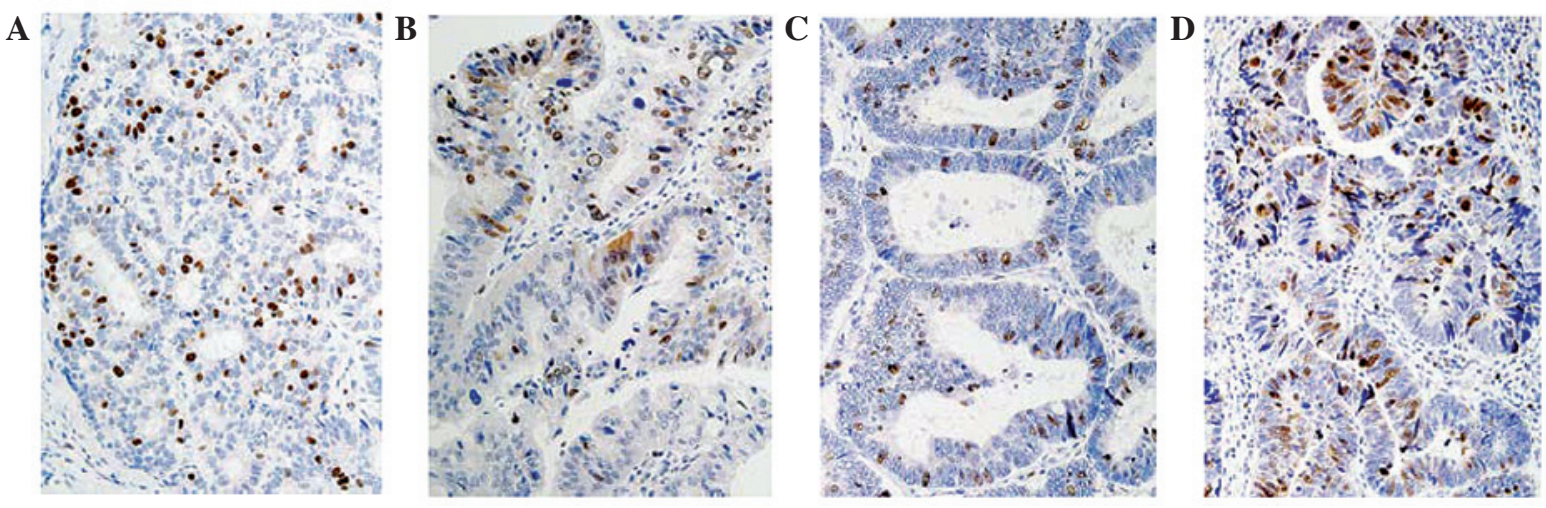

Figure 1. Immunohistochemical staining of CRM-1. Representative images of (A) nuclear CRM-1 and (B) cytoplasmic CRM-1 expression in gastric carcinoma, (C) nuclear CRM-1 expression in colon carcinoma and (D) cytoplasmic CRM-1 expression in rectal carcinoma (magnification, x200). CRM-1, chromosomal regional maintenance protein-1.

using immunohistochemistry and to the best of our knowledge, this method has not been used to detect this protein previously.

\section{Materials and methods}

Human tissue samples. A total of 69 advanced gastric adenocarcinoma specimens (33 intestinal type and 36 diffuse type) and 78 colorectal adenocarcinoma specimens (68 well- or moderately-differentiated and 10 poorly-differentiated) collected between April 2004 and October 2009 were obtained from the archives of the Department of Diagnostic Pathology, Osaka Red Cross Hospital (Osaka, Japan) and the Kobe Central Hospital of Social Insurance (Kobe, Japan). The histological typing was classified according to the Japanese Classification of gastric (30) or colorectal carcinoma (31). Histologically, papillary adenocarcinomas and tubular adenocarcinomas (well- or moderately-differentiated) were classified as intestinal type adenocarcinoma, whereas poorly-differentiated adenocarcinomas and signet ring cell carcinomas were classified as diffuse type adenocarcinoma. The median ages of the gastric and colorectal carcinoma patients were 72 (range, 41-94 years) and 67.5 years (range, 27-86 years), respectively. The gastric carcinoma group consisted of 48 male (70\%) and 21 female (30\%) patients, whereas the colorectal carcinoma group consisted of 44 male (56\%) and 34 female (44\%) patients. The present study was approved by the Ethics Committee of Kobe University Graduate School of Health Sciences (Kobe, Japan).

Immunohistochemistry. Formalin-fixed, paraffin-embedded surgically-resected tumor tissues were cut into 3- $\mu \mathrm{m}$ sections, and mounted on aminopropyltriethoxysilane-coated glass slides (Matsunami Glass, Osaka, Japan).

Slides were deparaffinized using xylene and dehydrated using a graded ethanol series. For antigen retrieval, the slides were immersed in $10-\mathrm{mM}$ citrate $(\mathrm{pH}$ 6.0) and heated to $>100^{\circ} \mathrm{C}$ for $10 \mathrm{~min}$ in a pressure cooker (Groupe SEB, Écully, France). After heating, the sections were cooled at room temperature in soaking solution for $30 \mathrm{~min}$ and washed with running tap water followed by $10 \mathrm{mM}$ phosphate-buffered saline (PBS; pH 7.2). After blocking in $0.25 \%$ casein in PBS
(Dako, Glostrup, Denmark), the sections were incubated overnight in PBS (negative control) or PBS containing a rabbit anti-CRM-1 monoclonal antibody (dilution, 1:1,200; catalog no. ab77977; Abcam, Cambridge, UK) at room temperature. To detect CRM-1, the sections were rinsed with PBS and incubated with Histofine Simple Stain MAX-PO (Nichirei Biosciences Inc., Tokyo, Japan) for $1 \mathrm{~h}$ at room temperature. Reaction products were then developed with 3,3'-diaminobenzidine and counterstained with Mayer's hematoxylin (Nacalai Tesque, Kyoto, Japan).

Immunostaining evaluation. At least five randomly selected fields were examined (magnification, x400) to determine the mean percentage of tumor cells expressing nuclear and/or cytoplasmic CRM-1. Samples in which $\geq 30 \%$ of the tumor cells exhibited nuclear staining or in which $\geq 15 \%$ of the tumor cells exhibited cytoplasmic staining were considered positive for CRM-1 protein expression. These cutoff values were based on the median observed values. All slides were evaluated by two independent investigators blinded to the experimental design.

Statistical analysis. $\chi^{2}$ test and Fisher's exact test were used to assess the CRM-1 expression levels of two groups. Spearman's rank correlation was used to assess correlations between two variables. $\mathrm{P}<0.05$ was considered to indicate a statistically significant difference. Statistical analysis was performed with Statcel 3 (OMS, Tokyo, Japan).

\section{Results}

Expression of CRM-1 in gastric carcinoma. CRM-1 was predominantly localized to the nucleus in gastric carcinoma tissue samples (Fig. 1). Nuclear expression of CRM-1 was observed in $61 \%(42 / 69)$ of samples and cytoplasmic CRM-1 expression was observed in 29\% (20/69) of samples (Table I). Nuclear CRM-1 was identified in $73 \%$ (24/33) of intestinal type tumors and $50 \%$ (18/36) of diffuse type tumors. Cytoplasmic CRM-1 was detected in 36\% (12/33) of intestinal type tumors and $22 \%(8 / 36)$ of diffuse type tumors. No significant differences were identified between CRM-1 expression in intestinal type and diffuse type tumors. 
Table I. Nuclear and cytoplasmic expression of CRM-1 in gastrointestinal and colorectal adenocarcinomas.

\begin{tabular}{lcc}
\hline & \multicolumn{2}{c}{ CRM-1 expression } \\
\cline { 2 - 3 } Cancer type & Nucleus, $\mathrm{n}(\%)$ & Cytoplasm, $\mathrm{n}(\%)$ \\
\hline Gastric adenocarcinoma $(\mathrm{n}=69)$ & $42(61)$ & $20(29)$ \\
Intestinal type $(\mathrm{n}=33)$ & $24(73)$ & $12(36)$ \\
Diffuse type $(\mathrm{n}=36)$ & $18(50)$ & $8(22)$ \\
Colorectal adenocarcinoma $(\mathrm{n}=78)$ & $43(55)$ & $29(37)$ \\
Well- to moderately-differentiated $(\mathrm{n}=68)$ & $40(59)$ & $29(43)$ \\
Poorly-differentiated $(\mathrm{n}=10)$ & $3(30)$ & $0(0)$ \\
\hline
\end{tabular}

Integers indicate the number of CRM-1-positive samples. CRM-1, chromosomal regional maintenance protein-1.

Table II. Correlation between CRM-1 and survivin expression in the nucleus and cytoplasm in gastric and colorectal carcinoma.

\begin{tabular}{|c|c|c|c|c|}
\hline \multirow[b]{2}{*}{ Cancer type } & \multicolumn{2}{|c|}{ Nuclear survivin } & \multicolumn{2}{|c|}{ Cytoplasmic survivin } \\
\hline & $\mathrm{r}$ & P-value & $\mathrm{r}$ & P-value \\
\hline \multicolumn{5}{|c|}{ Gastric carcinoma, total } \\
\hline N-CRM-1 & 0.484 & $<0.001^{\mathrm{a}}$ & 0.322 & $0.008^{\mathrm{a}}$ \\
\hline C-CRM-1 & 0.192 & 0.113 & 0.127 & 0.296 \\
\hline \multicolumn{5}{|c|}{ Gastric carcinoma, intestinal type } \\
\hline N-CRM-1 & 0.204 & 0.249 & 0.292 & 0.098 \\
\hline C-CRM-1 & 0.096 & 0.588 & 0.267 & 0.131 \\
\hline \multicolumn{5}{|c|}{ Gastric carcinoma, diffuse type } \\
\hline N-CRM-1 & 0.649 & $0.001^{\mathrm{a}}$ & 0.371 & $0.028^{\mathrm{a}}$ \\
\hline C-CRM-1 & 0.245 & 0.147 & 0.078 & 0.645 \\
\hline \multicolumn{5}{|c|}{ Colorectal carcinoma, total } \\
\hline N-CRM-1 & 0.338 & $0.003^{\mathrm{a}}$ & 0.299 & $0.009^{\mathrm{a}}$ \\
\hline C-CRM-1 & 0.254 & $0.026^{\mathrm{a}}$ & 0.268 & $0.019^{\mathrm{a}}$ \\
\hline
\end{tabular}

${ }^{a} \mathrm{P}<0.05$. CRM-1, chromosomal regional maintenance protein-1; N-CRM-1, nuclear CRM-1; C-CRM-1, cytoplasmic CRM-1.

Expression of CRM-1 incolorectal carcinoma. NuclearCRM-1 expression was observed in 55\% (43/78) and cytoplasmic CRM-1 expression in 37\% (29/78) of colorectal carcinoma samples (Table I). Nuclear CRM-1 was identified in 59\% (40/68) of well to moderately-differentiated tumors and $30 \%$ (3/10) of poorly-differentiated tumors. Cytoplasmic CRM-1 was observed in $43 \%$ (29/68) of well to moderately-differentiated tumors and none of the poorly-differentiated tumors.

Association between CRM-1 and survivin expression in gastric and colorectal carcinomas. The correlation between nuclear or cytoplasmic CRM-1 expression and nuclear or cytoplasmic survivin expression in gastric carcinoma (intestinal type and diffuse type) and colorectal carcinoma was evaluated (Table II). In intestinal type gastric carcinoma, no correlations were identified between any parameters. In diffuse type gastric carcinoma, nuclear CRM-1 expression was significantly correlated with nuclear $(\mathrm{r}=0.649 ; \mathrm{P}<0.001)$ and cytoplasmic $(\mathrm{r}=0.371 ; \mathrm{P}=0.028)$ expression of survivin.
In colorectal carcinoma, nuclear and cytoplasmic CRM-1 significantly correlated with nuclear and cytoplasmic survivin (nuclear CRM-1 and nuclear survivin, $\mathrm{r}=0.338 ; \mathrm{P}=0.003$; nuclear CRM-1 and cytoplasmic survivin, $\mathrm{r}=0.299 ; \mathrm{P}=0.009$; cytoplasmic CRM-1 and nuclear survivin, $r=0.254 ; \mathrm{P}=0.026$; cytoplasmic CRM-1 and cytoplasmic survivin, $\mathrm{r}=0.268$; $\mathrm{P}=0.019)$.

\section{Discussion}

Previous studies have implicated CRM-1 in carcinogenesis. CRM-1 expression has been found to correlate with a more aggressive tumor status and it has been suggested that CRM-1 may have prognostic value in gliomas, osteosarcomas, ovarian cancers and pancreatic cancers $(18,20,32,33)$. Previous studies have also demonstrated an association between CRM-1 expression and resistance to chemotherapy and thus, potent inhibitors of CRM-1 are currently being developed for use in cancer therapy. At present, members of the CRM-1 inhibitor 
family are novel therapeutic targets in renal cell carcinoma, non-small cell lung carcinoma and lymphoma (19,34-36).

The present study compared CRM-1 expression in gastric and colorectal carcinomas. To the best of our knowledge, this is the first study to report a correlation between CRM-1 and survivin expression using immunohistochemistry.

CRM-1 is predominantly found in the nucleus. In the present study, no significant differences in the nuclear or cytoplasmic expression rate of CRM-1 were identified between gastric and colorectal carcinomas. Furthermore, no significant differences in CRM-1 expression rate were identified between gastric carcinomas classified according to tumor type (differentiation status), although expression rates in both the nucleus and cytoplasm were higher in intestinal type gastric carcinomas than diffuse type gastric carcinomas. Zhou et al (23) reported that CRM-1 expression did not correlate with tumor differentiation status (poor vs. well to moderate). The authors also reported a higher CRM-1 expression rate in well to moderately-differentiated gastric adenocarcinomas compared with poorly-differentiated gastric adenocarcinomas (23). These results are consistent with those of the present study and suggest that no association exists between CRM-1 expression and tumor differentiation status in gastric carcinoma. A previous immunohistochemical analysis revealed that high CRM-1 expression was correlated with histological differentiation in esophageal squamous cell carcinoma but not pancreatic adenocarcinoma $(18,22)$. The association between CRM-1 expression level and histological tumor differentiation remains unclear. In the present study, the CRM-1 expression rates in well or moderately versus poorly-differentiated colorectal carcinomas could not be investigated accurately due to the large difference in sample sizes in each group.

In the present study, the association between CRM-1 and survivin expression in both the nucleus and cytoplasm was also investigated. In colorectal carcinoma, these parameters correlated in all expression patterns (nuclear and nuclear, cytoplasmic and cytoplasmic, and nuclear and cytoplasmic). In gastric carcinoma, no association between cytoplasmic CRM-1 expression and nuclear or cytoplasmic survivin expression was identified, whereas nuclear CRM-1 expression was found to correlate with nuclear or cytoplasmic survivin expression in diffuse but not intestinal type gastric carcinoma. These results indicate that CRM-1 expression patterns differ in gastric and colorectal carcinomas and suggest that CRM-1-mediated nuclear export of survivin may be deregulated in gastric carcinoma.

Recent studies have demonstrated that the survivin/CRM-1 axis exhibits an important function in regulating cell division and cell survival (1-3). Survivin shuttles proteins between the nucleus and cytoplasm $(37,38)$. When highly expressed in the cytoplasm, survivin may protect cancer cells by inhibiting apoptosis. In the nucleus, survivin predominantly associates with borealin, aurora B kinase and inner centrosome protein to form the chromosome passenger complex, which controls multiple processes during mitosis and is essential for genomic stability. Several studies have revealed that survivin is upregulated in the cytoplasm of cancer cells, where it prevents apoptosis and promotes tumor progression $(3-9,13)$. Elucidation of the mechanism by which CRM-1 modulates survivin expression in several tumor types would be of great importance, and clarification of CRM-1 expression patterns may aid in the selection of effective anticancer agents.

In conclusion, the present study revealed that CRM-1 is involved in survivin expression in gastric and colorectal carcinomas. We hypothesize that CRM-1 exhibits different functions in gastric and colorectal carcinoma. Further studies are required to determine whether CRM-1 expression is a prognostic predictor in these tumor types.

\section{Acknowledgements}

The authors would like to thank Dr Masayuki Shintaku (Osaka Red Cross Hospital) and Dr Toshihiko Miyake (Kobe Central Hospital of Social Insurance) for their support.

\section{References}

1. Li F, Ackermann EJ, Bennett CF, Rothermel AL, Plescia J, Tognin S, Villa A, Marchisio PC and Altieri DC: Pleiotropic cell-division defects and apoptosis induced by interference with survivin function. Nat Cell Biol 1: 461-466, 1999.

2. Li F and Ling X: Survivin study: An update of "what is the next wave"? J Cell Physiol 208: 476-486, 2006.

3. Knauer SK, Mann W and Stauber RH: Survivin's dual role: An export's view. Cell Cycle 6: 518-521, 2007.

4. Andersen MH, Svane IM, Becker JC and Straten PT: The universal character of the tumor-associated antigen survivin. Clin Cancer Res 13: 5991-5994, 2007.

5. Chen P, Li J, Ge LP, Dai CH and Li XQ: Prognostic value of survivin, X-linked inhibitor of apoptosis protein and second mitochondria-derived activator of caspases expression in advanced non-small-cell lung cancer patients. Respirology 15: 501-509, 2010.

6. Xiaoyuan C, Longbang C, Jinghua W, Xiaoxiang G, Huaicheng G, Qun Z and Haizhu S: Survivin: A potential prognostic marker and chemoradiotherapeutic target for colorectal cancer. Ir J Med Sci 179: 327-335, 2010.

7. Youssef NS, Hewedi IH and Abd Raboh NM: Immunohistochemical expression of survivin in breast carcinoma: Relationship with clinicopathological parameters, proliferation and molecular classification. J Egypt Natl Canc Inst 20: 348-357, 2008.

8. Wang TT, Qian XP and Liu BR: Survivin: Potential role in diagnosis, prognosis and targeted therapy of gastric cancer. World J Gastroenterol 13: 2784-2790, 2007.

9. Ito T, Shiraki K, Sugimoto K, Yamanaka T, Fujikawa K, Ito M, Takase K, Moriyama M, Kawano H, Hayashida M, et al: Survivin promotes cell proliferation in human hepatocellular carcinoma. Hepatology 31: 1080-1085, 2000.

10. Mita AC, Mita MM, Nawrocki ST and Giles FJ: Survivin: Key regulator of mitosis and apoptosis and novel target for cancer therapeutics. Clin Cancer Res 14: 5000-5005, 2008.

11. Miura K, Fujibuchi W, Ishida K, Naitoh T, Ogawa H, Ando T, Yazaki N, Watanabe K, Haneda S, Shibata C and Sasaki I: Inhibitor of apoptosis protein family as diagnostic markers and therapeutic targets of colorectal cancer. Surg Today 41: 175-182, 2011.

12. Sah NK, Khan Z, Khan GJ and Bisen PS: Structural, functional and therapeutic biology of survivin. Cancer Lett 244: 164-171, 2006.

13. Stauber RH, Mann W and Knauer SK: Nuclear and cytoplasmic survivin: Molecular mechanism, prognostic, and therapeutic potential. Cancer Res 67: 5999-6002, 2007.

14. Fornerod M, Ohno M, Yoshida M and Mattaj IW: CRM1 is an export receptor for leucine-rich nuclear export signals. Cell 90: 1051-1060, 1997.

15. Fukuda M, Asano S, Nakamura T, Adachi M, Yoshida M, Yanagida M and Nishida E: CRM1 is responsible for intracellular transport mediated by the nuclear export signal. Nature 390: 308-311, 1997.

16. Ossareh-Nazari B, Bachelerie F and Dargemont C: Evidence for a role of CRM1 in signal-mediated nuclear protein export. Science 278: 141-144, 1997.

17. Stade K, Ford CS, Guthrie C and Weis K: Exportin 1 (Crm1p) is an essential nuclear export factor. Cell 90: 1041-1050, 1997. 
18. Huang WY, Yue L, Qiu WS, Wang LW, Zhou XH and Sun YJ: Prognostic value of CRM1 in pancreas cancer. Clin Invest Med 32: E315-E321, 2009.

19. Inoue H, Kauffman M, Shacham S, Landesman Y, Yang J, Evans CP and Weiss RH: CRM1 blockade by selective inhibitors of nuclear export attenuates kidney cancer growth. J Urol 189: 2317-2326, 2013.

20. Noske A, Weichert W, Niesporek S, Röske A, Buckendahl AC, Koch I, Sehouli J, Dietel M and Denkert C: Expression of the nuclear export protein chromosomal region maintenance/exportin 1/Xpo1 is a prognostic factor in human ovarian cancer. Cancer 112: 1733-1743, 2008.

21. van der Watt PJ, Maske CP, Hendricks DT, Parker MI, Denny L, Govender D, Birrer MJ and Leaner VD: The Karyopherin proteins, $\mathrm{Crm} 1$ and Karyopherin beta1, are overexpressed in cervical cancer and are critical for cancer cell survival and proliferation. Int $\mathbf{J}$ Cancer 124: 1829-1840, 2009.

22. Yang X, Cheng L, Yao L, Ren H, Zhang S, Min X, Chen X, Zhang J and $\mathrm{Li} \mathrm{M}$ : Involvement of chromosome region maintenance 1 (CRM1) in the formation and progression of esophageal squamous cell carcinoma. Med Oncol 31: 155, 2014

23. Zhou F, Qiu W, Yao R, Xiang J, Sun X, Liu S, Lv J and Yue L: CRM1 is a novel independent prognostic factor for the poor prognosis of gastric carcinomas. Med Oncol 30: 726, 2013.

24. Hama H, Tabuchi T, Ito Y, Fukushima W, Matsunaga I, Miyashiro I and Nakayama T: Smoking behavior and participation in screening for lung, gastric, and colorectal cancers. Nihon Koshu Eisei Zasshi 63: 126-134, 2016 (In Japanese).

25. Nishimoto H, Katanoda K, Sato N, Sobue T, Mikami H: Cancer statistics in Japan 2014. Wakao F (ed). Center for Cancer Control and Information Services. National Cancer Center, 2015 (In Japanese).

26. Shintani M, Sangawa A, Yamao N and Kamoshida S: Immunohistochemical expression of nuclear and cytoplasmic survivin in gastrointestinal carcinoma. Int J Clin Exp Pathol 6: 2919-2927, 2013

27. Hutten S and Kehlenbach RH: CRM1-mediated nuclear export: To the pore and beyond. Trends Cell Biol 17: 193-201, 2007.

28. Knauer SK, Krämer OH, Knösel T, Engels K, Rödel F, Kovács AF, Dietmaier W, Klein-Hitpass L, Habtemichael N, Schweitzer A, et al: Nuclear export is essential for the tumor-promoting activity of survivin. FASEB J 21: 207-216, 2007.
29. Stauber RH, Rabenhorst U, Rekik A, Engels K, Bier C and Knauer SK: Nucleocytoplasmic shuttling and the biological activity of mouse survivin are regulated by an active nuclear export signal. Traffic 7: 1461-1472, 2006

30. Japanese Gastric Cancer Association: Japanese classification of gastric carcinoma. 3rd English edition. Gastric Cancer 14: 101-112, 2011.

31. Japanese Society for Cancer of the Colon and Rectum: Japanese Classification of Colorectal Carcinoma. 2nd English edition. Kanehara \& Co., Ltd., Tokyo, 2009.

32. Shen A, Wang Y, Zhao Y, Zou L, Sun L and Cheng C: Expression of CRM1 in human gliomas and its significance in p27 expression and clinical prognosis. Neurosurgery 65: 153-159, 2009

33. Yao Y, Dong Y, Lin F, Zhao H, Shen Z, Chen P, Sun YJ, Tang LN and Zheng SE: The expression of CRM1 is associated with prognosis in human osteosarcoma. Oncol Rep 21: 229-235, 2009.

34. Wang S, Han X, Wang J, Yao J and Shi Y: Antitumor effects of a novel chromosome region maintenance 1 (CRM1) inhibitor on non-small cell lung cancer cells in vitro and in mouse tumor xenografts. PLoS One 9: e89848, 2014.

35. Yashiroda Y and Yoshida M: Nucleo-cytoplasmic transport of proteins as a target for therapeutic drugs. Curr Med Chem 10: 741-748, 2003.

36. Zhang K, Wang M, Tamayo AT, Shacham S, Kauffman M, Lee J, Zhang L, Ou Z, Li C, Sun L, et al: Novel selective inhibitors of nuclear export CRM1 antagonists for therapy in mantle cell lymphoma. Exp Hematol 41: 67-78.e4, 2013.

37. Knauer SK, Bier C, Habtemichael N and Stauber RH: The Survivin-Crm1 interaction is essential for chromosomal passenger complex localization and function. EMBO Rep 7: 1259-1265, 2006.

38. Nguyen KT, Holloway MP and Altura RA: The CRM1 nuclear export protein in normal development and disease. Int $\mathrm{J}$ Biochem Mol Biol 3: 137-151, 2012. 